\title{
Pathological features of hypertrophic obstructive cardiomyopathy (HOCM) in the elderly
}

\author{
Ariela Pomerance ${ }^{1}$ and M. J. Davies \\ From the Department of Histopathology, Northwick Park Hospital, Harrow; and the \\ Department of Pathology, St. George's Hospital Medical School
}

The pathological findings and available clinical data in 15 necropsy cases of HOCM, aged over 6I years, are reported. Three patients were in the eighth decade and 4 in the ninth; 8 were women. Five cases presented as sudden death, 2 died in congestive cardiac failure, and 7 died of unrelated conditions and HOCM was an apparently incidental postmortem finding.

Compared with cases under 60 years, the hearts of the elderly patients were heavier and less likely to show typical asymmetrical hypertrophy, the free wall of the left ventricle also being thickened in two-thirds of the cases over 60 years. Most of the elderly cases showed a distinctive band of fibrous thickening over the upper part of the interventricular septum. This lesion had a 'mirror image' relation to the lower part of the aortic surface of the anterior mitral cusp, with the histological features of a friction lesion. It appears to be a morphological expression of the systolic contact of anterior mitral cusp and interventricular septum seen on cineangiography and thus diagnostic of HOCM. Once formed, the fibrous band appears to persist even if the obstructive element disappears. It is, therefore, a valuable diagnostic feature indicating a diagnosis of HOCM in an age group where the morphology is usually not the classical asymmetrical form and in which this diagnosis is usually not considered.

Hypertrophic obstructive cardiomyopathy (HOCM, idiopathic hypertrophic subaortic stenosis, or asymmetrical septal hypertrophy) is now a wellrecognized condition associated with sudden unexpected death as well as a cause of clinical cardiac disease. Young and middle-aged patients have predominated in the extensive literature which has accumulated following the descriptions of Brock (1957) and Teare (1958), and it is not yet widely appreciated that HOCM is also not uncommon in the elderly and may be apparently of no clinical significance.

In a recent review of some morphological features of HOCM (Davies, Pomerance, and Teare, 1974) we found that 14 of the 47 hearts studied were from patients over 60 years, 6 being over 70 . In the present communication we present clinical and pathological findings in these cases and a further case in an 84-year-old woman, compare them with those in younger patients, and emphasize a morphological feature which provides a useful diagnostic pointer in

Received 12 August 1974.

1 In receipt of a grant from the British Heart Foundation. an age group in which the diagnosis of HOCM may easily be overlooked.

\section{Subjects}

The 15 cases all came to necropsy in London and the Home Counties area between 1965 and 1974. In 2 cases a diagnosis of HOCM had been established in life by catheter studies and left ventricular cineangiography. These patients and 4 others died suddenly, though in one case death had been preceded by episodes of left ventricular failure. Two patients, both over 80 years, died of congestive cardiac failure, and in the remaining 7 cases HOCM was an apparently incidental necropsy finding. A family history suggesting heart disease was present in I case only (Case 7). However, only 2 cases had been fully investigated and the negative family histories in the remaining 13 cases were based on possibly incomplete histories taken on admission to geriatric or acute surgical wards, or obtained by the coroners' officers in cases of sudden death.

The pathological diagnoses of HOCM were initially made on the macroscopical features detailed in our earlier study (Davies et al., 1974), i.e. obvious left ventricular hypertrophy, either asymmetrical or, if 
FIG. I Opened left ventricle from Case I, a 72-yearold woman who died of septicaemia following cholecystitis. The entire free wall shows hypertrophy and a prominent bulging (incised) of the upper interventricular septum is present. A broad band of endocardial fibrous thickening with well-defined lower edge is seen on the upper part of the septum. symmetrical, accompanied by the characteristic septal subaortic fibrous band illustrated in Fig. $1,3,4$, and 5 . Typical histological changes, as shown in Fig. 2, were demonstrable in 13 cases, though examination of several blocks was often necessary. In the remaining 2 cases, diagnosis was made from photographs taken to record a subaortic septal fibrous lesion, whose significance, at the time of necropsy, had not yet been recognized by us. In these cases only a single septal block, taken through the fibrous band, was available for review.

The clinical and pathological data are summarized in the Table and representative cases reported in greater detail below.

\section{Case I: HOCM as in incidental postmortem finding}

A 72-year-old woman was admitted with a 2-week history of diarrhoea and vomiting. On examination she appeared collapsed, her blood pressure was 100/50 $\mathrm{mmHg}(13.3 / 6.7 \mathrm{kPa})$, and she had right-sided abdominal tenderness. She failed to respond to resuscitative measures. Three years previously she had complained of mild chest pain on exertion. Blood pressure then was $150 / 80 \mathrm{mmHg}(20.0 / 10.6 \mathrm{kPa})$, a soft pansystolic murmur was noted at the left sternal edge, and

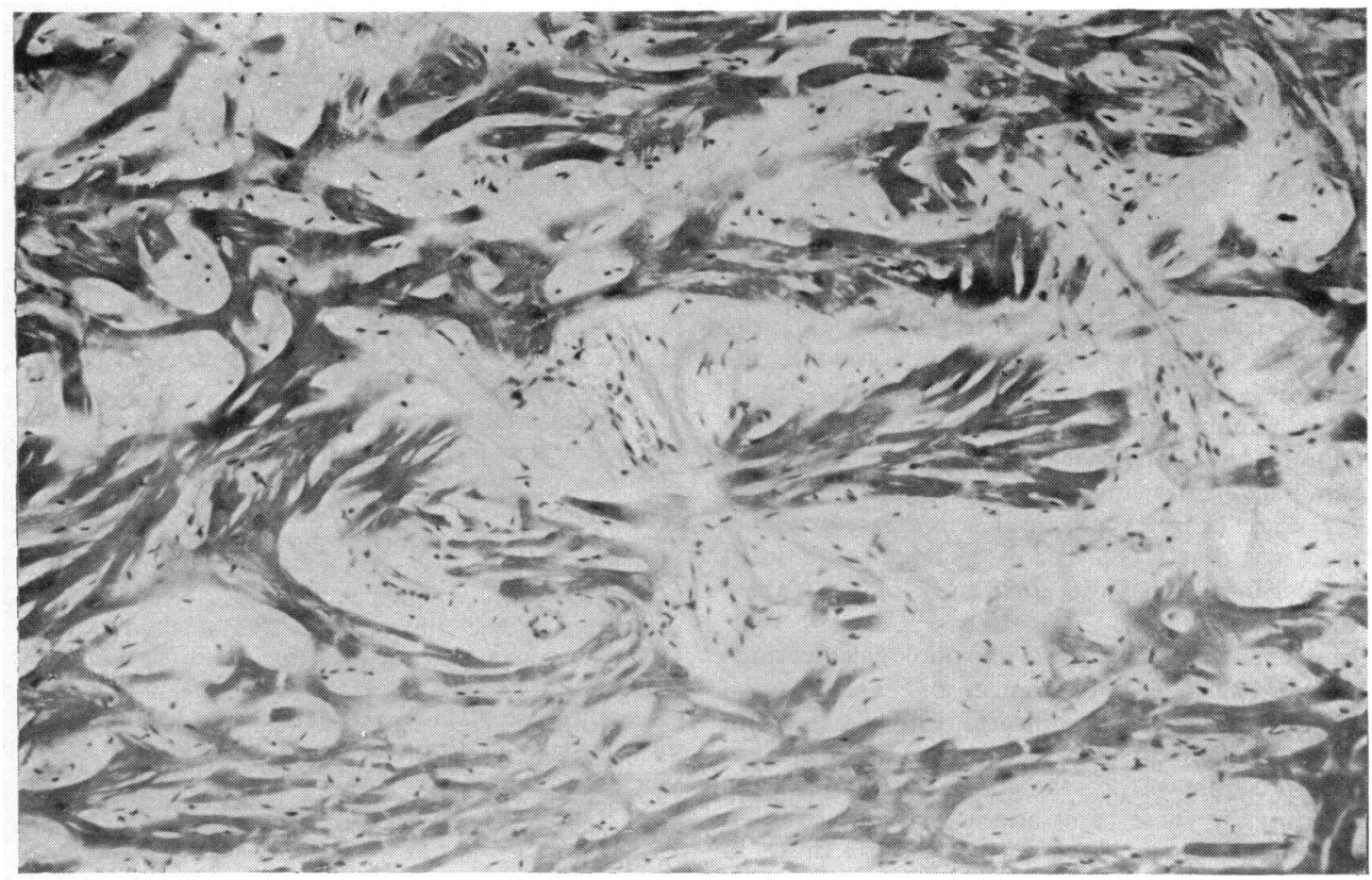

FIG. 2 Section of septal myocardium from Case $I$, showing the disorganized architecture, fibrosis, large thick abnormally branched myofibres, and 'whorl' formation typical of HOCM. (Haematoxylin and eosin. $\times 61$.) 


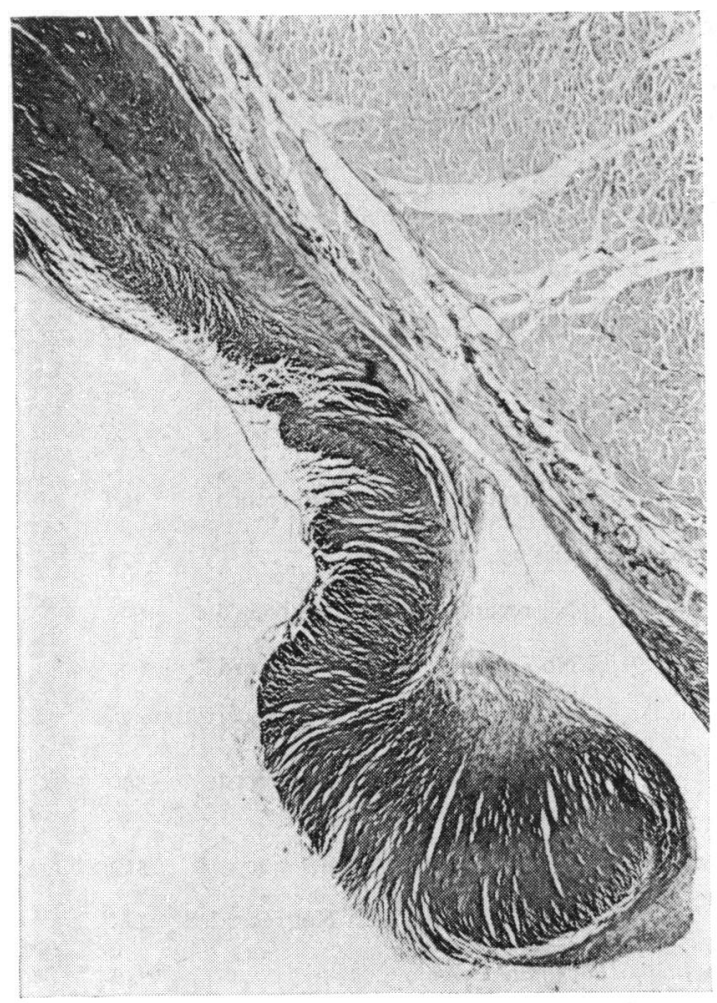

FIG. 3 Section through the subaortic band at its lower (apical) part, showing the superficial localization of the fibrosis and the valve-like arrangement of dense collagen, scanty elastic fibres, and endothelialized loose connective tissue (Case I). (Elastic van Gieson. $\times$ i4.)

an electrocardiogram showed atrial fibrillation and changes suggesting ischaemia in the left ventricular leads. She was treated with digitalis, returned to normal rhythm, and remained well until her final admission.

Necropsy showed severe acute cholecystitis with staphylococcal empyema of the gallbladder and early peritonitis. The heart (Fig. I) was enlarged, weighing $535 \mathrm{~g}$, and showed pronounced left ventricular hypertrophy involving the entire free wall but most prominent in the upper part of the interventricular septum. A conspicuous band of white endocardial thickening approximately $1.5 \mathrm{~cm}$ deep was noted on the hypertrophied septum about $0.5 \mathrm{~cm}$ below the aortic valve base. This had a sharply defined lower (apical) margin and on superimposing the anterior mitral valve cusp (seen reflected in Fig. I) on the interventricular septum it was apparent that the subaortic band and aortic surface of the mitral cusp were mirror-images of each other. The mitral cusp also showed a minor degree of flat white thickening of its distal part of its aortic aspect. The posterior mitral cusp and other valves were normal. A pronounced degree of calcified atheroma was noted but there was no macroscopical myocardial fibrosis or necrosis.

Microscopy of blocks from the thickened septum showed areas of disorganized myofibre architecture, with short broad abnormally branched fibres interrupted by fibrous tissue and occasional groups of fibres arranged in whorls (Fig. 2). These appearances correspond to those described by Teare (1958) and Paré et al. (196I) in their cases of sudden death in young adults and are now considered diagnostic of HOCM (Olsen, 1971, I972; Van Norden, Olsen, and Pearse, 1971). The subaortic band consisted of superficial endocardial fibroelastic proliferation, the microscopical features (Fig. 3) being indistinguishable from those of jet and friction lesions of more usual aetiologies (Edwards and Burchell, 1958; Salazar and Edwards, 1970).

\section{Case 7: sudden death in clinically diagnosed HOCM}

A 63-year-old woman, known to have had 'heart trouble for years', collapsed and died while visiting relatives in Hertfordshire and postmortem examination was requested by H.M. Coroner. Abnormal findings were limited to the heart, which weighed $675 \mathrm{~g}$ and showed conspicuous concentric left ventricular hypertrophy with mild fibrous streaking visible on the cut surfaces (Fig. 4). The right ventricular cavity was also greatly restricted by the hypertrophied septum. Though there was no strikingly disproportionate septal hypertrophy and the left ventricular cavity was not disproportionately small, a diagnosis of HOCM was indicated by the presence of the characteristic subaortic fibrous band corresponding to the distal part of the anterior mitral cusp. Moderate flat fibrous thickening of the aortic surface of this cusp was also visible. The mitral valve ring was extensively calcified with a spur of calcium ulcerating through the atrial surface of the posterior cusp near the commissure. This calcification was of the common senile type and there was no other valvular abnormality. The coronary arteries were large, widely patent, and showed minimal atheroma only. Microscopical findings were almost identical to those in Case I, differing only in a slightly greater amount of fibrous tissue.

This patient had been attending the Brompton Hospital and Dr. M. Honey kindly supplied the clinical summaries. She had initially presented, aged 55, with chest pain on exertion. She had had two uneventful pregnancies and no relevant past illnesses. Two sibs were known to have had heart murmurs. On examination she was in intermittent atrial fibrillation, her blood pressure was $180 / 95 \mathrm{mmHg}(23.9 / 12.6 \mathrm{kPa})$, and a grade 3, systolic murmur was present in the aortic area with a grade 3 non-conducted pansystolic murmur in the mitral area.

On cardiac catheterization a gradient of $95 \mathrm{mmHg}$ (12.6 kPa) was present between the aorta and left ventricle and left ventricular cineangiography showed the characteristic appearances of HOCM. She remained fairly well for about five years, then developed episodes of weakness and dizziness. Electrocardiogram then 
TABLE Morphological and clinical features of HOCM in elderly patients

\begin{tabular}{|c|c|c|c|c|c|c|c|}
\hline \multirow{2}{*}{$\begin{array}{l}\text { Case } \\
\text { No. }\end{array}$} & \multirow{2}{*}{$\begin{array}{l}\text { Age } \\
(y r)\end{array}$} & \multirow[t]{2}{*}{$\operatorname{Sex}$} & \multirow[t]{2}{*}{ Presentation and/or mode of death } & \multicolumn{2}{|c|}{ Blood pressure } & \multirow{2}{*}{$\begin{array}{l}\text { Systolic } \\
\text { murmur } \\
\text { present }\end{array}$} & \multirow{2}{*}{$\begin{array}{l}\text { Heart } \\
\text { weight }(g) \\
\text { (total) }\end{array}$} \\
\hline & & & & $m m H g$ & $k P a$ & & \\
\hline I & 72 & $\mathbf{F}$ & $\begin{array}{l}\text { Acute abdomen; septicaemia from staphylo- } \\
\text { coccal cholecystitis }\end{array}$ & $150 / 80$ & $20.0 / 10.6$ & + & 535 \\
\hline 2 & 76 & $\mathbf{M}$ & Chest signs; carcinoma of bronchus & $180 / 100$ & $23.9 / 13.3$ & Not recorded & 275 \\
\hline 3 & 67 & $\mathbf{M}$ & Urinary tract symptoms; carcinoma of bladder & $170 / 90$ & $22.6 / 12.0$ & No record & 450 \\
\hline 4 & 69 & $\mathbf{M}$ & Obstructive jaundice; carcinoma of bronchus & $150 / 90$ & $20.0 / 12.0$ & + & 530 \\
\hline 5 & 72 & $\mathbf{F}$ & Carcinoma of bronchus & Iro/70 & $\mathrm{I} 4.6 / 9.3$ & + & 410 \\
\hline 6 & 84 & $\mathbf{F}$ & Carcinoma of bladder & \multicolumn{2}{|c|}{ No record } & No record & 360 \\
\hline 7 & 63 & $\mathbf{F}$ & $\begin{array}{l}\text { Anginal pain; HOCM diagnosed } 6 \text { years } \\
\text { before death; sudden death }\end{array}$ & $180 / 95$ & $23.9 / 12.6$ & + & 675 \\
\hline 8 & 61 & $\mathrm{~F}$ & Chest pain and sudden death & No recor & & No record & 700 \\
\hline 9 & 61 & $\mathbf{M}$ & Sudden death & No recur & & No record & 600 \\
\hline 10 & 66 & $\mathbf{M}$ & Sudden death & No recor & & No record & 610 \\
\hline II & $6 I$ & $\mathbf{M}$ & Sudden death & No recor & & No record & 340 \\
\hline 12 & 87 & $\mathbf{F}$ & $\begin{array}{l}\text { Chronic bronchitis and congestive cardiac } \\
\text { failure }\end{array}$ & $160 / 100$ & $21.3 / 13 \cdot 3$ & + & 510 \\
\hline 13 & 81 & $\mathbf{F}$ & Congestive cardiac failure & $100 / 70$ & $13.3 / 9.3$ & Not recorded & 485 \\
\hline 14 & 65 & $\mathbf{M}$ & $\begin{array}{l}\text { Chest pain, not clearly related to effort; } \\
\text { HOCM diagnosed on left ventricular } \\
\text { angiography; sudden death preceded by } \\
\text { episodes of left ventricular failure }\end{array}$ & $140 / 70$ & $18.6 / 9.3$ & + & 740 \\
\hline 15 & 84 & $\mathbf{F}$ & $\begin{array}{l}\text { Gastrointestinal tract haemorrhage; acute on } \\
\text { chronic bronchitis }\end{array}$ & No recor & & No record & 380 \\
\hline
\end{tabular}

^ Single block through subaortic band only available for review.

showed periods of asystole during transition from atrial fibrillation to sinus rhythm. The arrhythmia stabilized after insertion of a temporary demand pacemaker and digoxin and propranolol. She was discharged on digoxin $0.25 \mathrm{mg}$ daily and no further attacks had been reported on outpatient follow-up.

\section{Case 8: unexpected sudden death}

A 6I-year-old woman complained of chest pain after a car journey, and collapsed and died after climbing a flight of stairs. Postmortem examination showed a greatly hypertrophied heart, weighing $700 \mathrm{~g}$. Apart from a slightly greater degree of left ventricular dilatation and absence of mitral ring calcification, the appearances were almost identical with those described for Case 7, with conspicuous hypertrophy of free wall and septum and the characteristic subaortic fibrous band (Fig. 5). Microscopy also showed areas with the characteristic abnormalities of myofibres and fibrosis seen in the previous specimens. The valves were normal apart from the minor thickening of the anterior mitral cusp and the coronary arteries showed mild atheroma only.

\section{Case 12: congestive cardiac failure, clinically unsuspected HOCM}

An 87-year-old woman was admitted to a geriatric hospital and died with a clinical diagnosis of chronic bronchitis and congestive cardiac failure. She had a history of ' heart trouble for years' but no further details could be obtained. On admission her blood pressure was $160 / 100 \mathrm{mmHg}(21.3 / 13.3 \mathrm{kPa})$ and atrial fibrillation was present, together with the physical signs of congestive cardiac failure. A pansystolic murmur was noted. Necropsy was performed at the request of H.M. Coroner by Professor D. Teare. The heart weighed $5 \mathrm{ro} \mathrm{g}$ and showed considerable left ventricular hypertrophy affecting mainly the septum and anterior wall of the left ventricle. The left ventricular cavity was small and a typical subaortic fibrous band was present. The valves showed no significant abnormality. Microscopy showed 


\begin{tabular}{|c|c|c|}
\hline $\begin{array}{l}\text { Subaortic } \\
\text { band } \\
\text { present }\end{array}$ & Distribution of hypertrophy & $\begin{array}{l}\text { Typical } \\
\text { histology }\end{array}$ \\
\hline+ & $\begin{array}{l}\text { Septum and whole free wall } \\
\text { left ventricle }\end{array}$ & + \\
\hline- & $\begin{array}{l}\text { Septum and anterior wall } \\
\text { left ventricle }\end{array}$ & + \\
\hline- & $\begin{array}{l}\text { Septum and anterior wall } \\
\text { left ventricle }\end{array}$ & + \\
\hline+ & $\begin{array}{l}\text { Septum and whole free wall } \\
\text { left ventricle }\end{array}$ & $\star$ \\
\hline+ & $\begin{array}{l}\text { Septum and whole free wall } \\
\text { left ventricle }\end{array}$ & $\star$ \\
\hline+ & $\begin{array}{l}\text { Septum and whole free wall } \\
\text { left ventricle }\end{array}$ & + \\
\hline+ & $\begin{array}{l}\text { Septum and whole free wall } \\
\text { left ventricle }\end{array}$ & + \\
\hline+ & $\begin{array}{l}\text { Septum and whole free wall } \\
\text { left ventricle }\end{array}$ & + \\
\hline \multirow[t]{2}{*}{-} & $\begin{array}{l}\text { Septum and anterior wall } \\
\text { left ventricle }\end{array}$ & + \\
\hline & $\begin{array}{l}\text { Posterolateral wall left } \\
\text { ventricle and posterior septum }\end{array}$ & + \\
\hline+ & $\begin{array}{l}\text { Septum, whole free wall left } \\
\text { ventricle, and part of anterior } \\
\text { wall right ventricle }\end{array}$ & + \\
\hline+ & $\begin{array}{l}\text { Septum and anterior wall } \\
\text { left ventricle }\end{array}$ & + \\
\hline+ & $\begin{array}{l}\text { Septum and free wall left } \\
\text { ventricle }\end{array}$ & + \\
\hline+ & $\begin{array}{l}\text { Septum and free wall left } \\
\text { ventricle }\end{array}$ & + \\
\hline+ & $\begin{array}{l}\text { Septum and whole free wall } \\
\text { left ventricle }\end{array}$ & + \\
\hline
\end{tabular}

areas of abnormal myofibre architecture and fibrosis, as in the previous cases.

\section{Comparison of findings with those in cases under 60 years}

HOCM in the elderly differs in presentation, sex incidence, extent of ventricular hypertrophy, and frequency of a subaortic fibrous band. The condition most often presents to the pathologist as a case of sudden death, and this was so in $27(82 \%)$ of our 33 cases under 60 years (Davies et al., 1974). In contrast, only 5 of the 15 cases over 60 years presented as sudden death and these were the youngest cases. The largest group among the elderly patients were the 7 cases in which HOCM was an apparently incidental finding.

Half of the patients over 60 years were women, in contrast to the male predominance $(82 \%)$ in the younger cases. This finding agrees with the high proportion of women in the elderly patients in recent clinical reports
(Penther et al., 1970; Whiting et al., 197I ; Alday et al., I973).

The average heart weight was higher in the older patients, $506 \mathrm{~g}$ compared with $435 \mathrm{~g}$ in the cases under 60 years. The whole left ventricle appeared hypertrophied in 10 of the 15 cases over 60 years, while under 60 years a similar proportion, two-thirds, showed typical asymmetrical hypertrophy only; the free wall of the left ventricle was thickened in only II cases.

\section{Discussion}

HOCM is still widely regarded as a disease of the young and middle-aged only. Until recently the published reports contained only a few isolated case reports of HOCM in elderly patients, 60 years apparently being the accepted upper limit of ' middleage' (Sanders et al., 1966; Warkentin and Korns, 1967; Ewy et al., 1968). However, in more recent clinical series the condition has been recorded with considerable frequency in the elderly. The 133 patients with HOCM studied by Penther and his colleagues (1970) included 9 over 60 and 4 over 70 years, $14(32 \%)$ of Whiting et al.'s (197r) 44 cases were over 6o, as were 18 per cent of Tajik, AssadMorell, and Giuliani's (1973) 95 cases and 8 of the 45 studied by Alday et al. (1973). It is clear that HOCM can no longer be regarded as an unlikely diagnosis in older patients. The age distribution of the cases in our recent pathological review (Davies et al., 1974) was in agreement with those recent studies from other countries; I4 (30\%) of the 47 hearts studied were from patients over 60 years and 6 of those had been over 70 years.

The morphology and presentation of HOCM in the elderly differed from that usually found in young and middle-aged patients. The hearts from cases over 60 years were heavier and more likely to have hypertrophy of the left ventricular free wall as well as the interventricular septum, and most showed a distinctive band of fibrous endocardial thickening over the upper part of the interventricular septum. A similar high incidence of this lesion was present in Penther $e t$ al.'s (1970) fatal cases. It was noted in all 6 patients dying over 55 years, but was present in only $\mathrm{I}$ of the 5 patients younger than 55 . This band is clearly related to contact with the anterior mitral cusp, a relation that can easily be demonstrated post mortem by allowing the cusp to come into contact with the septum, when the configuration of the distal margin of the band will be seen to correspond with that of the distal edge of the aortic face of the cusp. Microscopically the features are identical with those of endocardial 'pockets', jet lesions, and endocardial friction lesions caused by altered chordal/ ventricular relation (Edwards and Burchell, 1958; 


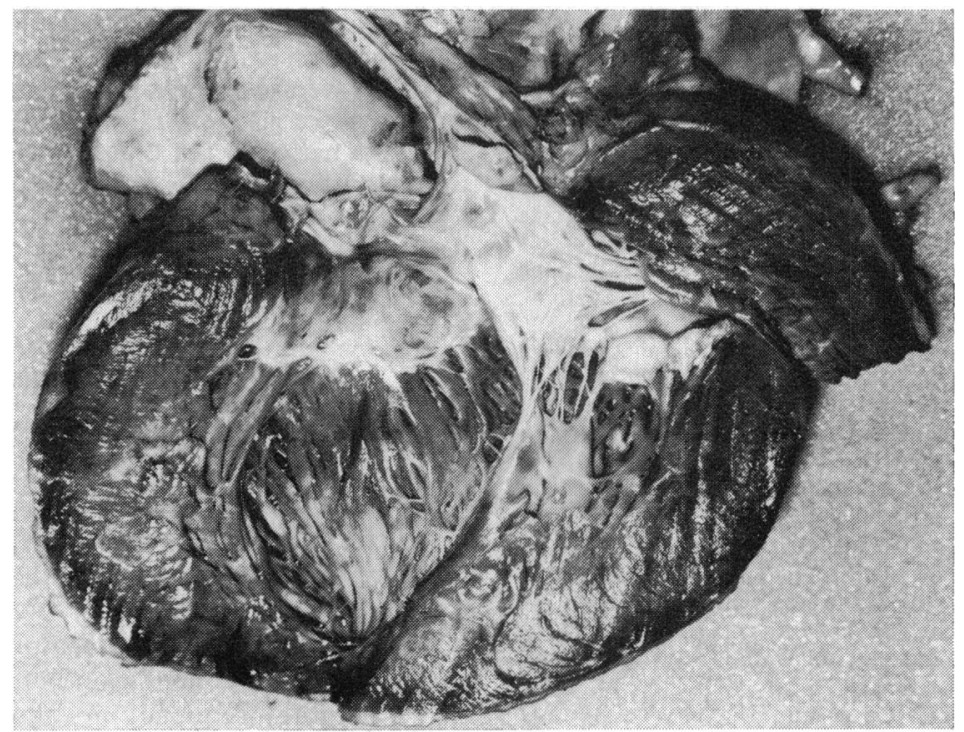

FIG. 4 Opened left ventricle from Case 7, a 63-year-old woman with clinically diagnosed HOCM who died suddenly. There is striking symmetrical thickening of the left ventricle. $A$ typical subaortic band is present, its lower (apical) edge a 'mirror image' of the distal part of the aortic surface of the anterior mitral cusp.

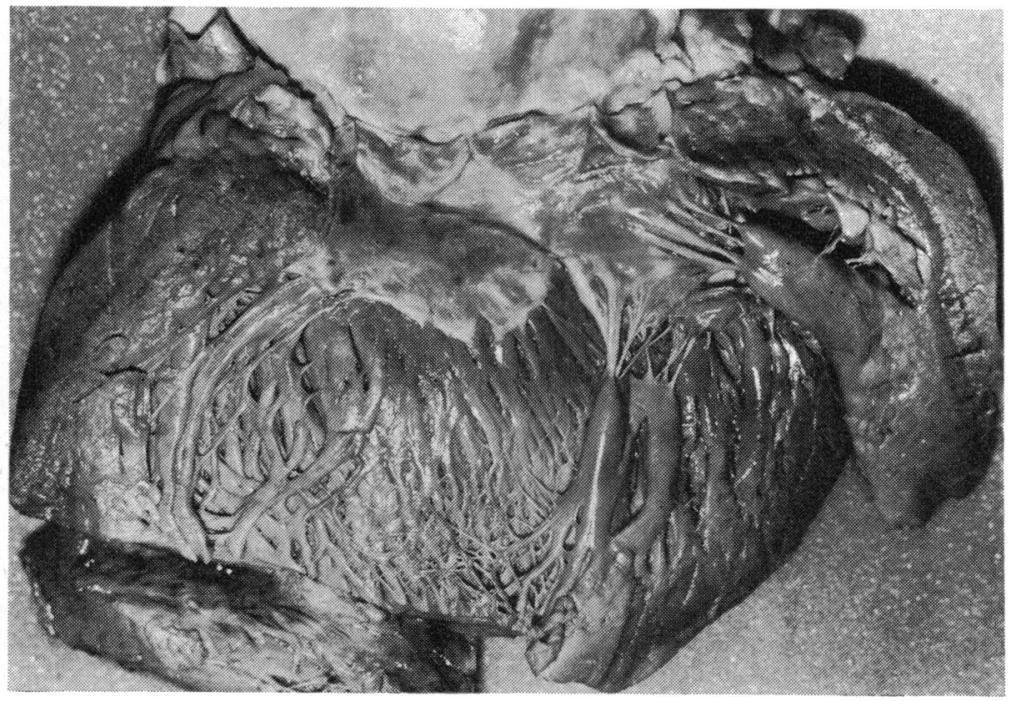

FIG. 5 Opened left ventricle from Case 8, a 6r-year-old woman dying suddenly and unexpectedly. The entire left ventricular myocardium is thickened and the cavity slightly dilated. The characteristic subaortic band and its relation to the anterior mitral cusp are well seen. Patchy white thickening of the rough zone of the cusp is also present. 


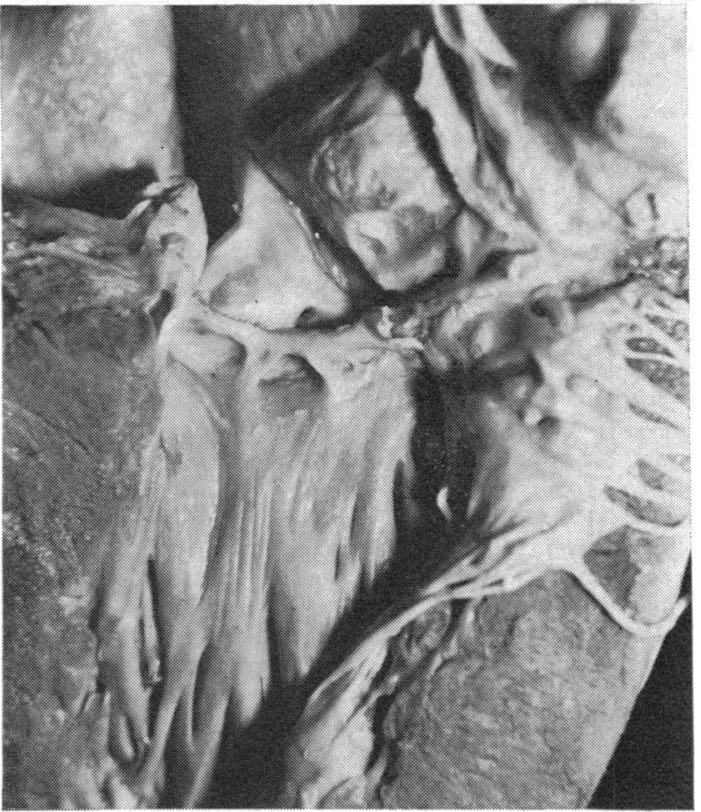

FIG. 6 Fibrous congenital subaortic stenosis, for comparison with the subaortic bands in Fig. 1,4 , and 5 . The stenosing subaortic ridge is more protuberant and sharply defined, is situated nearer the aortic base, and extends onto the aortic aspect of the anterior mitral cusp. From a 75-year-old man, known to have had an aortic systolic murmur for most of his life.

Salazar and Edwards, 1970). This lesion, therefore, appears to be a morphological expression of the systolic contact between anterior mitral cusp and interventricular septum which is a diagnostic feature of HOCM on cineangiography (Simon, Ross, and Gault, 1967) and may thus justifiably be considered diagnostic of HOCM when observed in the opened heart. Since it is a form of chronic friction lesion, its frequency is likely to be related to duration of obstruction and the high incidence in older patients, therefore, not surprising. The greater incidence of hypertrophy affecting the left ventricular free wall, and higher heart weights in the elderly patients are also attributable to more longstanding obstruction.

The subaortic fibrous septal band of HOCM is easily distinguished from the fibrous ridge of congenital subaortic stenosis which may, very rarely, also be encountered in elderly patients (Fig. 6). The latter is more protuberant, very sharply localized, situated nearer the base of the aortic cusps, and usually extends onto the aortic face of the anterior mitral cusp near its attached margin.
Endocardial thickening of the left ventricular outflow tract has been noted in several of the earlier papers on HOCM (Brachfield and Gorlin, 1959; Menges, Brandenburg, and Brown, I96I; Stampbach and Senn, 1962; Braunwald et al., 1964; Kittle, Reed, and Crockett, I964; Warkentin and Korns, 1967; Edwards, 1965), but its distinctive features and diagnostic value do not appear to have been fully appreciated. We have emphasized this finding because of its diagnostic value in cases where the heart does not show the easily recognized asymmetrical hypertrophy described by Teare (1958). Once formed, the subaortic band remains visible even in hearts in which the asymmetry and characteristic small left ventricular cavity can no longer be seen (as in Fig. I, 4, and 5). Though it is generally believed that cavity dilatation does not occur in HOCM, we have occasionally noted left ventricular cavities in excess of $55 \mathrm{ml}$ and these have been seen in patients with clinically proven disease.

Our experience suggests that it is in the hearts of elderly patients that the morphological features are least likely to be of classical type and HOCM most likely to be unrecognized. Ischaemic and hypertensive heart disease are so commonly causes of death in patients over 60 years that in the absence of any contradictory evidence left ventricular hypertrophy is understandably usually attributed to one or both of these aetiologies. Where blood pressure was known to have been normal and the coronary arteries were free from significant narrowing, cardiac hypertrophy will probably be ascribed to congestive cardiomyopathy unless the characteristic subaortic band is observed and its significance recognized.

Our early awareness of the subaortic band as a diagnostic feature of HOCM was undoubtedly responsible for recognition of the condition in 5 of the 7 elderly patients who died of unrelated diseases, without any symptoms of cardiac disease. The concept that hypertrophic cardiomyopathy may be present without apparent clinical consequences is a very recent one though the variable and often long clinical course of diagnosed HOCM is well documented (Frank and Braunwald, 1968; Parker, 1969; Goodwin, 1973; Hardarson et al., 1973). However, echocardiographic studies have now demonstrated asymmetrical septal hypertrophy in asymptomatic relatives of patients with HOCM, including people over 70 years (Henry, Clark, and Epstein, 1973). These authors put forward the concept of a spectrum of HOCM, ranging from severely symptomatic outflow obstruction to asymptomatic septal hypertrophy of no apparent clinical significance. Our pathological studies support this concept, the cases reported in the present communication 
ranging from those with a known clinical diagnosis of HOCM to those dying suddenly with undoubted pathological evidence of this condition but no known clinical symptoms.

We are grateful to Dr. M. Honey for clinical details and permission to include Case 7, to Dr. K. Misch for the heart of Case I, and to Professor D. Teare for those of Cases 9-12 and 14. The example of congenital subaortic stenosis was kindly contributed by Dr. W. Killpack.

\section{References}

Alday, L. E., Moreyra, E., Amuchastegui, L. M., and Madoery, J. (1973). Recognising and treating muscular subaortic stenosis. Geriatrics, 28, 74 .

Brachfeld, N., and Gorlin, R. (1959). Subaortic stenosis: a revised concept of the disease. Medicine, 38, 4I5.

Braunwald, E., Lambrew, C. T., Rockoff, S. D., Ross, J., and Morrow, A. G. (1964). Idiopathic hypertrophic subaortic stenosis. I. A description of the disease based upon an analysis of 64 patients. Circulation, 30, Suppl. IV, 3 .

Brock, R. (1957). Functional obstruction of the left ventricle (acquired aortic subvalvar stenosis). Guy's Hospital Reports, 106, 221.

Davies, M. J., Pomerance, A., and Teare, R. D. (1974). Pathological features of hypertrophic obstructive cardiomyopathy (HOCM). Fournal of Clinical Pathology, 27, 529.

Edwards, J. E. (1965). Pathology of left ventricular outflow tract obstruction. Circulation, 31, 586.

Edwards, J. E., and Burchell, H. B. (1958). Endocardial and intimal lesions (jet impact) as possible sites of origin of murmurs. Circulation, 18, 946.

Ewy, G. A., Marcus, F. I., Bohajalian, O., Burke, H. L., and Roberts, W. C. (1968). Muscular subaortic stenosis: clinical and pathologic observations in an elderly patient. American fournal of Cardiology, 22, 126.

Frank, S., and Braunwald, E. (1968). Idiopathic hypertrophic subaortic stenosis: clinical analysis of 126 patients with emphasis on the natural history. Circulation, 37, 759.

Goodwin, J. F. (1973). Hypertrophic diseases of the myocardium. Progress in Cardiovascular Diseases, 16, 199.

Hardarson, T., de la Calzada, C. S., Curiel, R., and Goodwin, J. F. (1973). Prognosis and mortality of hypertrophic obstructive cardiomyopathy. Lancet, 2, 1462.

Henry, W. L., Clark, C. E., and Epstein, S. E. (1973). Asymmetric septal hypertrophy (ASH): the unifying link in the IHSS disease spectrum: observations regarding its pathogenesis, pathophysiology and course. Circulation, 47, 827.

Kittle, C. F., Reed, W. A., and Crockett, J. E. (1964). Infundibulectomy for subaortic hypertrophic stenosis. Circulation, 29, Suppl. I, Ir9.
Menges, H., Brandenburg, R. O., and Brown, A. L. (1961). Clinical, hemodynamic, and pathologic diagnosis of muscular subvalvular aortic stenosis. Circulation, 24, I 126.

Olsen, E. G. J. (1971). Morbid anatomy and histology in hypertrophic obstructive cardiomyopathy. In Hypertrophic Obstructive Cardiomyopathy, pp. 183-191. Ed. by G. E. W. Wolstenholme and M. O'Connor. Churchill, London.

Olsen, E. G. J. (1972). Pathology of primary cardiomyopathies. Postgraduate Medical fournal, 48, 732.

Paré, J. A. P., Fraser, R. G., Pirozynski, W. J., Shanks, J. A., and Stubington, D. (1961). Hereditary cardiovascular dysplasia: a form of familial cardiomyopathy. American Fournal of Medicine, 31, 37.

Parker, B. M. (1969). The course in idiopathic hypertrophic muscular subaortic stenosis. Annals of Internal Medicine, 70, 903 .

Penther, P., Cousteau, J. P., Gay, J., Maurice, P., and Lenegre, J. (1970). Some peculiar aspects of obstructive cardiomyopathy of subjects over 55 years of age (with reference to 14 cases). Archives des Maladies du Coeur et des Vaisseaux, 63, 1230.

Salazar, A. E., and Edwards, J. E. (1970). Friction lesions of ventricular endocardium: relation to chordae tendineae of mitral valve. Archives of Pathology, 90, 364.

Sanders, C. A., Austen, W. G., Jordan, J. C., and Scanell, J. G. (1966). Idiopathic hypertrophic subaortic stenosis in two elderly siblings. New England fournal of Medicine, 274, I254.

Simon, A. L., Ross, J., and Gault, J. H. (1967). Angiographic anatomy of the left ventricle and mitral valve in idiopathic hypertrophic subaortic stenosis. Circulation, 36, 852.

Stampbach, O., and Senn, A. (1962). Die idiopathische hypertrophische subaortenstenose. Schweizerische medizinische Wochenschrift, 92, 125.

Tajik, A. J., Assad-Morell, J. L., and Giuliani, E. R. (1973). Hypertrophic obstructive cardiomyopathy in the elderly. American Heart fournal, 85, 574.

Teare, D. (1958). Asymmetrical hypertrophy of the heart in young adults. British Heart fournal, 20, 1.

Van Noorden, S., Olsen, E. G. J., and Pearse, A. G. E. (I97I). Hypertrophic obstructive cardiomyopathy, a histological, histochemical, and ultrastructural study of biopsy material. Cardiovascular Research, 5, 118.

Warkentin, D. L., and Korns, M. E. (1967). Hypertrophic subaortic stenosis in the aged. American Heart fournal, 73, I06.

Whiting, R. B., Powell, W. J., Dinsmore, R. E., and Sanders, C. A. (1971). Idiopathic hypertrophic subaortic stenosis in the elderly. New England fournal of Medicine, 285, 196.

Requests for reprints to Dr. Ariela Pomerance, Histopathology Department, Northwick Park Hospital, Watford Road, Harrow, Middlesex HAI $3 \mathrm{UJ}$. 